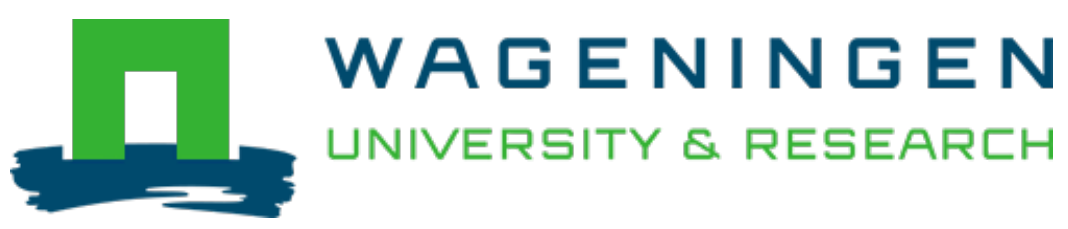

\title{
Field-scale molecular testing of virulent potato soft rot Pectobacteriaceae in Norway
}

\author{
European Journal of Plant Pathology \\ Rossmann, Simeon; Dees, Merete Wiken; Torp, Torfinn; Le, Ving Hong; Skogen, Monica et al \\ https://doi.org/10.1007/s10658-019-01901-0
}

This article is made publicly available in the institutional repository of Wageningen University and Research, under the terms of article $25 \mathrm{fa}$ of the Dutch Copyright Act, also known as the Amendment Taverne. This has been done with explicit consent by the author.

Article 25 fa states that the author of a short scientific work funded either wholly or partially by Dutch public funds is entitled to make that work publicly available for no consideration following a reasonable period of time after the work was first published, provided that clear reference is made to the source of the first publication of the work.

This publication is distributed under The Association of Universities in the Netherlands (VSNU) 'Article $25 \mathrm{fa}$ implementation' project. In this project research outputs of researchers employed by Dutch Universities that comply with the legal requirements of Article $25 \mathrm{fa}$ of the Dutch Copyright Act are distributed online and free of cost or other barriers in institutional repositories. Research outputs are distributed six months after their first online publication in the original published version and with proper attribution to the source of the original publication.

You are permitted to download and use the publication for personal purposes. All rights remain with the author(s) and / or copyright owner(s) of this work. Any use of the publication or parts of it other than authorised under article $25 \mathrm{fa}$ of the Dutch Copyright act is prohibited. Wageningen University \& Research and the author(s) of this publication shall not be held responsible or liable for any damages resulting from your (re)use of this publication.

For questions regarding the public availability of this article please contact openscience.library@,wur.nl 


\title{
Field-scale molecular testing of virulent potato soft rot Pectobacteriaceae in Norway
}

\author{
Simeon Rossmann • Merete Wiken Dees • Torfinn Torp • Vinh Hong Le • \\ Monica Skogen • Borghild Glorvigen • Jan van der Wolf • May Bente Brurberg
}

C Koninklijke Nederlandse Planteziektenkundige Vereniging 2019

\begin{abstract}
Potato soft rot Pectobacteriaceae (SRP) cause large yield losses and are persistent in seed lots once established. In Norway, different Pectobacterium species are the predominant cause of soft rot and blackleg disease. This work aimed to evaluate the potential of real-time PCR for quantification of SRP in seed tubers, as well as investigating the status of potato seed health with respect to SRP in Norway. A total of 34 seed potato lots, including
\end{abstract}

Electronic supplementary material The online version of this article (https://doi.org/10.1007/s10658-019-01901-0) contains supplementary material, which is available to authorized users.

S. Rossmann · M. W. Dees • V. H. Le · M. Skogen •

M. B. Brurberg

Division of Biotechnology and Plant Health, Norwegian Institute of Bioeconomy Research (NIBIO), P.O. Box 115, 1431 Ås, Norway

\section{S. Rossmann • M. B. Brurberg $(\bowtie)$}

Department of Plant Sciences, Norwegian University of Life Sciences (NMBU), P.O. Box 5003 NMBU, 1432 Ås, Norway e-mail: may.brurberg@nibio.no

T. Torp

Department of Research, Norwegian Institute of Bioeconomy

Research (NIBIO), P.O. Box 115, 1431 Ås, Norway

B. Glorvigen

Norwegian Agricultural Extension Service (NLR), Osloveien 1, 1433 Ås, Norway

J. van der Wolf

Biointeractions and Plant Health, Wageningen University \& Research (WUR), P.O. Box 16, 6700AA, Wageningen,

Netherlands certified seeds, was grown and monitored over three consecutive years. All seed lots contained a quantifiable amount of SRP after enrichment, with very few subsamples being free of the pathogens. A high SRP prevalence based on a qPCR assay, as well as a high symptom incidence in certified seeds were observed, suggesting that current criteria for seed certification are insufficient to determine tuber health and predict field outcomes. Pectobacterium atrosepticum was the most abundant species in the examined seed lots and present in all lots. Consistently good performance of first generation seed lots with respect to blackleg and soft rot incidence, as well as low quantity of SRP in these seed lots demonstrated the importance of clean seed potatoes. Weather conditions during the growing season seemed to govern disease incidence and SRP prevalence more than seed grade. The impact of temperature, potato cultivar and Pectobacterium species on tuber soft rot development were further examined in tuber infection experiments, which showed that temperature was the most important factor in nearly all cultivars. Large-scale quantification of latent infection and predictive models that include contributing factors like weather, infecting bacterial species and cultivar are needed to reduce soft rot and blackleg.

Keywords Pectobacterium atrosepticum .

Pectobacterium parmentieri - Pectobacterium polaris .

Dickeya solani $\cdot$ Blackleg 


\section{Introduction}

Potatoes are among the most important food crops worldwide and play a particularly central role in Norwegian agriculture. Bacterial soft rot diseases, including blackleg and tuber soft rot, caused by members of the genera Pectobacterium and Dickeya are a serious challenge in potato production worldwide. These genera are genetically diverse, composed of various species with different host preferences and geographical locations (Ma et al. 2007; Dees et al. 2017a). Globally, Dickeya solani, D. dianthicola, D. dadantii, Pectobacterium atrosepticum, $P$. carotovorum subsp. brasiliense and P. parmentieri are responsible for the most devastating outbreaks (van der Wolf et al. 2014; van der Wolf et al. 2017; Ma et al. 2018). In Norway, P. atrosepticum, $P$. carotovorum subsp. carotovorum, and to a lesser extent, $P$. parmentieri and $P$. polaris are the dominant potato soft rot species (Dees et al. 2017a; Dees et al. 2017b).

Soft rot Pectobacteriaceae (SRP) cause disease by secreting a variety of plant cell wall degrading enzymes that macerate the plant tissue, leading to a typically soft rot. The enzyme composition is species and strain dependent, and efficiency of the enzymes varies with temperature (Smadja et al. 2004; Glasner et al. 2008). In potato, tuber soft rot can occur both in the soil and in storage after uptake. Rotting of the seed tubers can prevent emergence of the plants, which can lead to yield losses in infected seed lots (Pérombelon et al. 1988). Tissue maceration can also occur in roots, stolons and the stems (Czajkowski et al. 2010b). Blackleg is a rotting lesion of the stem, signified by its black colour, typically occurring after soft rot of the mother tuber and spread of the pathogen through the vascular system of a sprouted plant (Pérombelon et al. 1989). Blackleg may also lead to wilting of the plants and stunted growth, either in addition to or without a visible lesion of the stem (Pérombelon and Kelman 1987). Entry of SRP in aboveground wounds of the plant can lead to systemic infection and aerial stem rot, a less heavy rot of the haulm (Pérombelon 2002; Czajkowski et al. 2010a).

Farming machinery and contact between tubers in storage are thought to facilitate transmission of SRP from diseased to healthy plants and tubers (Czajkowski et al. 2011). Transmission to healthy plants can also occur during field growth. The bacteria are motile, given sufficient soil moisture, and can infect roots and tubers of plants in their proximity by entering lenticels or wounds (Czajkowski et al. 2011). Systemic colonization of potato plants after entry through wounded and intact roots was demonstrated for a GFP-labelled Dickeya strain (Czajkowski et al. 2010b). SRP can therefore rapidly accumulate within a few field generations (Czajkowski et al. 2011). The main source of infection of an initially unaffected seed lot is still unknown. Recently, large-scale presence of SRP in insects found in Norwegian potato fields was demonstrated, including in a field with first generation prebasic seed tubers (Rossmann et al. 2018). This offers a possible explanation for the initial infection of clean seeds.

The development of blackleg or soft rot symptoms in a given plant or tuber is difficult to predict, and depends on many factors. These include environmental conditions, the phytobiome, health status and genotype of the host, and the infecting soft rot strain (Pérombelon 2002; Gill et al. 2014; Czajkowski et al. 2011; Dees et al. 2017a; van der Wolf et al. 2017). Water saturated soil and consequently low oxygen levels around the roots and tuber, stress the plants and favour bacterial growth (Pérombelon 2002). Such conditions often occur after heavy rainfall in fields with inadequate water draining capacity. Furthermore, D. solani and P. c. subsp. brasiliense, as well as some $P$. c. subsp. carotovorum strains seem to prefer warmer temperatures than P. atrosepticum (du Raan et al. 2016). Additionally, calcium amendments in soils with low calcium content have been shown to decrease susceptibility of tubers to soft rot (Ngadze et al. 2014). While most commercial potato cultivars are susceptible to soft rot, cultivars with less susceptibility towards blackleg and soft rot have been uncovered in various studies (Lyon 1989; Chung et al. 2013). However, reliable screening for cultivars that are less susceptible to blackleg and soft rot is not trivial due to the influence of environmental factors on disease development (Czajkowski et al. 2011; Gill et al. 2014).

SRP can remain latent for a long time, complicating efficient detection and control. Several diagnostic methods of SRP detection and identification are available, including immunological assays, fatty acid analysis, and other biochemical assays. Currently, molecular tools, mainly quantitative real-time PCR (qPCR), are most commonly used for detection and identification in research and plant health diagnostics, due to their accuracy and efficiency (Czajkowski et al. 2015). However, in seed certification schemes, symptom incidence 
of soft rot and blackleg in field inspections are routinely used for quality assessment.

During the last years, major blackleg occurrence, and incidents of non-emergence due to rotting seed tubers have been reported by Norwegian seed growers. This work was conducted to test the following hypotheses:

1. Quantitative real-time PCR (qPCR) is a suitable diagnostic tool for the assessment of SRP prevalence on a large scale.

2. Environmental and host factors, as well as present SRP species affect seed health of Norwegian potatoes.

To test these hypotheses, SRP were quantified in 34 seed lots over three years using qPCR at three different stages (planting, harvest, after storage), and symptoms were assessed on the plants and tubers. In addition, the SRP species D. solani, P. atrosepticum and $P$. parmentieri were detected and quantified separately using qPCR. The role of potato cultivar, SRP species and temperature during infection was examined further for 15 common Norwegian potato cultivars in a controlled environment using $P$. atrosepticum and a Norwegian isolate of the newly described $P$. polaris.

\section{Materials and methods}

Potato material

Norwegian seed potatoes are certified according to health status, producer certification and number of generations after production of clones from tissue culture. An overview of the different stages in Norwegian seed potato production is given in Supplementary Table 1 . While detailed requirements vary, the Norwegian certification scheme is comparable to current potato seed certification requirements given by the European Union (EU), as described in the Council Directive 2002/56/EC. Seed lots with qualities varying from Pre-Basic 2 (P2) to Certified (C) were selected for this work, in addition to some disqualified lots and some of unknown seed quality (Table 1). The three cultivars Asterix (table potato), Innovator (fries), Lady Claire (crisps), were examined. The tubers used in this study were provided by various seed producers, and Pre-Basic 2 (P2) material was provided by Overhalla Klonavlssenter AS (Minituber and prebasic seed centre).
Field trial

The 34 examined seed lots were grown at a test field site located in Hedmark, a county and important potato production area in the southeast of Norway, for three consecutive years. An overview of the seed lots grown each year, their quality according to the Norwegian certification scheme and the times of planting, haulm killing and harvest is provided in Table 1. They were grown in multiple (non-random) rows per seed lot, sorted by cultivar with $25 \mathrm{~cm}$ planting distance between each tuber. Some material was grown over two consecutive years after storage. The setup of the field study was not randomized due to practical concerns, and selection of seed lots varied in certified quality between years and cultivars. While this expanded the range of seed lot types that were analysed, it restricted the possibilities of downstream statistical analysis. Farming conditions on the field were typical concerning fertilization, as well as interval treatment for weed, fungus and insect control. Haulms were killed chemically (Diquat).

Assessment of soft rot and blackleg, and quantification of SRP by qPCR

Blackleg symptoms were registered by thorough field inspection towards the end of the growing season, 80 days (2015), 86 days (2016), and 97 days (2017) after planting. The tubers were analysed just before planting, immediately after harvest and after three months of storage. From harvest to analysis, the samples were stored in $25 \mathrm{~kg}$ paper sacks (multiple per seed lot) in a climate room at $4{ }^{\circ} \mathrm{C}, 85 \% \mathrm{RH}$ and darkness. At each sampling time (planting, harvest and after storage), eight $(2015)$ or six $(2016,2017)$ samples of 25 tubers were analysed from each seed lot. The tubers were kept for two weeks at $16{ }^{\circ} \mathrm{C}$. Then, samples were rinsed in tap water, air-dried, and visually assessed for symptoms of soft rot. Tubers were cut in halves and packed into separate vacuum bags per sample of 25 tubers. Bags were vacuum-sealed using common kitchen appliances (Food Sealer Pro, OBH Nordica; corresponding Food Sealer bags) and left for 5 days at $20{ }^{\circ} \mathrm{C}$ (modified from Boomsma et al. 2013). The liquid that formed in the bags due to tuber degradation was taken out $(5 \times 1 \mathrm{ml}$ if sufficient material) after vigorous shaking of the bags to assure homogenous distribution of bacteria regardless of motility or localisation in the bag. This liquid was then used for DNA extraction using KingFisher Cell and 
Table 1 Cultivars, seed lots, and their quality according to the Norwegian certification scheme, used in the field study. Abbreviations used: As = Asterix, In = Innovator, L. C. = Lady Claire, D = disqualified seed; $\mathrm{U}=$ Unknown quality; the abbreviations commonly used in the Norwegian seed certification scheme are detailed in Supplementary Table 1. Numbers in front of the letter identify the individual seed lots and are not indicative of seed quality. Additional information, such as the detailed seed lot quality, is given in parentheses. Dates (month/day) for planting, haulm killing and harvest are provided

\begin{tabular}{|c|c|c|c|c|c|c|c|c|c|c|}
\hline \multirow[b]{2}{*}{ Yr. } & \multirow[b]{2}{*}{ Var. } & \multicolumn{6}{|c|}{ Seed lot number } & \multirow[t]{2}{*}{ Planting } & \multirow{2}{*}{$\begin{array}{l}\text { Haulm } \\
\text { killing }\end{array}$} & \multirow[t]{2}{*}{ Harvest } \\
\hline & & 1 & 2 & 3 & 4 & 5 & 6 & & & \\
\hline \multirow[t]{3}{*}{2015} & As & $1 \mathrm{D}$ & $2 \mathrm{D}$ & $3 \mathrm{D}$ & $4 \mathrm{D}$ & $5 \mathrm{D}$ & $6 \mathrm{D}$ & $06 / 11$ & 09/19 & $10 / 12$ \\
\hline & In & $1 \mathrm{U}$ & $2 \mathrm{U}$ & $3 \mathrm{U}$ & $4 \mathrm{U}$ & $5 \mathrm{U}$ & & $06 / 12$ & $09 / 19$ & $10 / 12$ \\
\hline & L. C. & $1 \mathrm{U}$ & $2 \mathrm{U}$ & $3 \mathrm{U}$ & $4 \mathrm{U}$ & & & $06 / 12$ & 09/19 & $10 / 12$ \\
\hline \multirow[t]{3}{*}{2016} & As & $\mathrm{P} 2$ & $1 \mathrm{C}$ & $2 \mathrm{C}$ & $3 \mathrm{C}$ & & & $06 / 10$ & $09 / 17$ & $10 / 10-12$ \\
\hline & In & $\mathrm{P} 2$ & 1B & 2B (B1) & $3 \mathrm{~B}$ & & & $06 / 13$ & $09 / 17$ & $10 / 10$ \\
\hline & L. C. & $\mathrm{P} 2$ & 1B (B1) & 2B (B3) & 3B (B2) & & & 06/13-14 & $09 / 17$ & $10 / 05$ \\
\hline \multirow[t]{3}{*}{2017} & As & $\mathrm{P} 2$ & $\begin{array}{l}\text { "P3" } \\
\text { (Replant of } 2016 \text { P2) }\end{array}$ & $1 \mathrm{C}$ & $2 \mathrm{C}$ & & & $06 / 15$ & $09 / 25$ & $10 / 10$ \\
\hline & In & $\mathrm{P} 2$ & $\begin{array}{l}\text { "P3" } \\
\text { (Replant of } 2016 \text { P2) }\end{array}$ & “B2” (Replant of 2016 B1) & $2 \mathrm{~B}$ & & & $06 / 15$ & $09 / 25$ & $10 / 10-11$ \\
\hline & L. C. & $\mathrm{P} 2$ & $\begin{array}{l}\text { "P3" } \\
\text { (Replant of } 2016 \text { P2) }\end{array}$ & “B2" (Replant of 2016 B1) & $\mathrm{U}$ & & & $06 / 15$ & $09 / 25$ & $10 / 10-11$ \\
\hline
\end{tabular}

Tissue DNA kit (Thermo Scientific) on the Kingfisher Duo Prime platform according to the manufacturer's instructions. SRP DNA was detected and quantified from four to six samples per seed lot using the generic PEC Taqman primer/probe set from Pritchard et al. (2013) as described before (Rossmann et al. 2018). Quantities were calculated based on a standard curve of genomic DNA from $P$. atrosepticum strain OKDS 42-1-12 (Dees et al. 2017a). The standard curve for quantification using the PEC assay was calculated based on $P$. atrosepticum as it was assumed that a large part of present SRP belongs to this species, however amplification efficiency of the assay may vary somewhat for different species. Species-specific Taqman assays were used to determine the presence of $P$. atrosepticum, P. parmentieri and D. solani in the samples, as described by Pritchard et al. (2013), and van der Wolf et al. (2017). The quantification cycle $(\mathrm{Cq})$ values were averaged from two technical replicates for four to six samples per seed lot. If one technical replicate had no signal, the sample was regarded negative.

\section{Tuber infection test}

First-generation clonal potato tubers (P2) of 15 different cultivars commonly used in Norwegian potato farming were inoculated with two SRP strains and incubated at two temperatures to measure the impact of these factors on rot progression. The cultivars used in this experiment were Asterix, Beate, Berber, Cerisa, Erika, Fakse, Folva, Hassel, Innovator, Lady Britta, Lady Claire, Lunarossa, Mandel, Nansen, and Rutt. The Pectobacterium strains used for inoculation were $P$. atrosepticum strain PK782-1-2-13 (Dees et al. 2017a) and P. polaris strain NIBIO1006 (Dees et al. 2017b). The two strains were selected because they are more aggressive than other strains of their respective species, as determined in previous tuber infection tests (Dees et al. 2017a; Dees et al. 2017b). The tuber infection assay was performed as previously described with modifications (Laurila et al. 2008; Dees et al. 2017b). The bacteria were grown on LB plates at room temperature for 2-3 days, and suspended in phosphate-saline buffer (PBS) to an optical density (OD) of $0.8 \pm 0.05$ at a wavelength of $600 \mathrm{~nm}$. For each strain, $10 \mu \mathrm{l}$ was inoculated into wounds of each of 15 tubers of each cultivar. Wounding and inoculation was done by puncturing the tubers with a thin pipette tip $(20 \mu$ filter tip) and injecting the bacterial solution into the wound. The pipette tips were left in the wounds to reduce air contact at the inoculation site. Five tubers of each cultivar were inoculated with PBS as a control. The inoculated tubers were placed in trays $(50 \times 29 \times 6 \mathrm{~cm})$, lined with a filter paper soaked with $50 \mathrm{ml}$ Milli-Q $\mathrm{H}_{2} \mathrm{O}$, and each tray was wrapped in plastic to promote high humidity and low oxygen conditions. The trays were incubated at a room temperature 
of $24.2{ }^{\circ} \mathrm{C} \pm 0.6$ (SD) for 3 days. Separate trays were used for each cultivar. After incubation, the macerated tissue was removed with a scalpel and weighed. The same experimental setup was used in a culture room with a temperature of $19.5^{\circ} \mathrm{C} \pm 0.2$ (SD) for 3 days. The two temperatures are rounded to 20 and $24{ }^{\circ} \mathrm{C}$ throughout the manuscript. For each temperature, the 15 cultivars were split up randomly into two groups with eight and seven cultivars respectively and tested separately due to practical restrictions. To control comparability between the separate tests, two full sets of 35 tubers of the cultivar Asterix (15 for each infecting strain and five control infections) were tested at $20{ }^{\circ} \mathrm{C}$ to gain insight into variations between experiments. The results were consistent and pooled in the analysis.

\section{Statistical analysis}

To analyse differences between the mean SRP quantities at the different sampling points, one-way ANOVAs on the prevalence data were performed for each year separately. The linear model for a given year was formulated as.

$\mathrm{y}_{i j}=\mu+\tau_{i}+\varepsilon_{i j}$

The model assumed $\mathrm{y}_{i j}$ as an observation $j$ of SRP quantity in $\log 10$ (ng DNA) from the qPCR assay as the response variable of sampling time $i$. It assumed $\tau_{i}$ to be the main effect of sampling time $i$, and $\varepsilon_{i j}$ as the random error associated with $\mathrm{y}_{i j}$. The parameters $\mu$ and $\tau_{i}$ were unknown and estimated from the data, the error $\varepsilon_{i j}$ was independent. This simplified approach was used to obtain a generalized overview of the trends within a year that is unaffected by the high variation of seed quality between lots and biases in the data, such as the overrepresentation of lower-quality seed lots for Asterix compared to the other two cultivars (Table 1). Pairwise comparisons of the means using Tukey's method with a $95 \%$ confidence interval were performed to find significant differences between sampling times and group them accordingly (detailed modelling results in Supplementary Table 3).

To examine the influence of cultivar, sampling time and year on the SRP quantity after enrichment, mixed model ANOVAs were used on prevalence data from seed lots with a certified seed quality of B and $\mathrm{P} 2$ respectively. This analysis was restricted to comparisons within a given seed quality to reduce diversity of the samples and thereby confounding factors. Furthermore, the data measured at planting was excluded from this analysis since the year was assumed not to influence SRP quantity at planting. The resulting model was formulated as:

$$
\mathrm{y}_{i j k l m}=\mu+\tau_{i}+\alpha_{j}+\beta_{k}+\mathrm{S}_{1(\mathrm{j})}+(\tau \beta)_{i k}+\varepsilon_{i j k l m}
$$

This model assumed $\mathrm{y}_{i j k l m}$ as an observation $m$ of SRP quantity in $\log 10$ (ng DNA) from the qPCR assay as the response variable of the sampling time $i$, the cultivar $j$, and the year $k$. The seed lot $l$ was included as a random factor nested within the cultivar. Furthermore, $\tau_{i}$ was assumed the main effect of the sampling time $i, \alpha_{j}$ the main effect of the cultivar $j, \beta_{k}$ the main effect of the year $k, \mathrm{~S}_{1(\mathrm{j})}$ the random effect of the seed lot 1 (nested within the cultivar $\mathrm{j}$ ), and $(\tau \beta)_{i k}$ the interaction effect of the sampling time $i$ and the year $k$. Additionally, $\varepsilon_{i j k l m}$ was assumed the random error associated with $\mathrm{y}_{i j k l m}$. The parameters $\mu, \tau_{i}, \alpha_{j}, \beta_{k}$, and $(\tau \beta)_{i k}$ were unknown and estimated from the data, while the random components $\mathrm{S}_{1(\mathrm{j})}$ and $\varepsilon_{i j k l m}$ were all independent. The factor interactions other than $(\tau)_{i k}$ were omitted since they could not be estimated reliably across the three different data sets (B-quality seeds with/without replanted lots, P2-quality seeds) and therefore did not allow homogenous analysis. Omitting these interactions did not decrease $\mathrm{R}^{2}$ values of the models by more than 3 percentage points in cases where they could partially be estimated and therefore only had minor impact on the analysis. To determine significant differences and group the categories of the main effects accordingly, pairwise comparisons using the Tukey method with a $95 \%$ confidence interval were performed for the main effects. The statistical analysis of the SRP quantification data was performed in MiniTab 18.1.

The tuber infection experiment was analysed by ANOVA with cultivar, temperature, strain, and all interactions as independent factors. The three-way linear model used in the ANOVA of the tuber infections was formulated as:

$$
\begin{aligned}
\mathrm{y}_{i j k l}= & \mu+\alpha_{i}+\beta_{j}+\gamma_{k}+(\alpha \beta)_{i j}+(\alpha \gamma)_{i k}+(\beta \gamma)_{j k} \\
& +(\alpha \beta \gamma)_{i j k}+\varepsilon_{i j k l}
\end{aligned}
$$

This model assumed $\mathrm{y}_{i j k l}$ as the observation $l$ of rotten tissue in $\mathrm{g}$ of cultivar $i$, temperature $j$ and strain $k$. It furthermore assumed $\alpha_{i}$ as the main effect of cultivar $i$, $\beta_{j}$ as the main effect of temperature $j$, and $\gamma_{k}$ as the main effect of strain $k$. All interaction effects were included in the model and denoted accordingly, and $\varepsilon_{i j k l}$ was 
assumed the random error associated with $\mathrm{y}_{i j k l}$. The parameters $\mu, \alpha_{i}, \beta_{j}, \gamma_{k},(\alpha \beta)_{i j},(\alpha \gamma)_{i k},(\beta \gamma)_{j k}$ and $(\alpha \beta \gamma)_{i j k}$ were unknown and estimated from the data, the errors $\varepsilon_{i j k l}$ were independent. After the three-way ANOVA, grouping was performed according to comparisons by cultivar, as well as all combinations of cultivars, temperatures, and strains, using Tukey's pairwise comparisons with a $95 \%$ confidence interval. The calculations were performed using Minitab 17.2.1.

The pairwise comparisons of tuber maceration between strains and temperatures shown in Fig. 5 were performed using the Wilcoxon test for all combinations of temperature and infecting strain within a cultivar. The $p$ values were adjusted for the familywise error rate across all tests in all cultivars using the HolmBonferroni method. The calculations were performed in $\mathrm{R}$ version 3.6 using the rstatix package v0.2.0 (Kassambara 2019b) and visualized using the packages ggplot2 (Wickham 2016) and ggpubr v0.2.3 (Kassambara 2019a).

Weather data

Weather data was obtained from two measurement stations in Kongsvinger municipality in Hedmark county. The average monthly temperature and precipitation data was obtained from the eklima database of the Norwegian Meteorological Institute, reporting from a site approx. $8 \mathrm{~km}$ from the field site. The ground temperature at a distance of approx. $0.5 \mathrm{~km}$ from the field site was obtained through Agrometeorology Norway.

\section{Results}

A total of 34 seed potato lots were grown and monitored over three consecutive years (Table 1). In 2017, offspring of five of the seed lots from 2016 were grown in addition to new seed lots. In 2016 and 2017, P2 seeds were grown as an indicator of clean seeds with minimal SRP presence. Using qPCR, the amount of bacterial DNA in samples taken from the seed lots was quantified. This was done with a general assay, detecting all SRP species, and with species-specific assays, to identify the SRP species P. atrosepticum, P. parmentieri, and D. solani. However, the presence of SRP, even in comparatively high quantities, did not necessarily result in symptomatic disease as measured by blackleg and soft rot incidence. Throughout the manuscript, the word 'prevalence' refers to the description and discussion of SRP infection as measured by qPCR, while the word 'incidence' refers to observed disease symptoms.

SRP infection prevalence and influencing factors

All seed lots contained a quantifiable amount of bacteria and the quantities varied between the 25-tuber samples measured from a given seed lot (Fig. 1). The quantification showed differences in the SRP prevalence between samples taken at planting, harvest and after storage in all years (Fig. 1, Supplementary Table 3). In 2015, the average quantity of SRP in the samples increased steadily from planting to harvest, to the last sampling after three months of storage. In 2016, the average amount at planting and harvest was similar to the respective sampling times in 2015, but a significant decrease was measured after storage. In 2017, the average levels were low for samples taken at planting and harvest but were significantly higher after three months of storage (Fig. 1). While not all seed lots followed these trends in a given year, the trends were largely consistent between seed lots and cultivars. A notable exception are the Innovator seed lots in 2017, which contained low SRP quantities at all sampling points, compared to the other cultivars. The weather during the growing seasons varied between the years in the area of the field site (Fig. 2).

An ANOVA of the SRP prevalence in samples of seed qualities B and P2 showed the year to be a significant factor in explaining variance in B-quality tubers but not $\mathrm{P} 2$ quality tubers (Fig. 3). In the ANOVA for B-quality tubers without and with replanted seed lots $\left(\mathrm{R}^{2}=51.2 / 64.91 \%\right)$, the year $(F=18.35 / 28.38)$ and the interaction between year and sampling time $(\mathrm{F}=19.04 / 69.26)$ contributed significantly to the observed variability between samples with $p<0.05$ (Supplementary Table 4) and mean SRP quantities after enrichment in 2016 and 2017 were significantly different (Fig. 3). For P2-quality tubers on the other hand, ANOVA $\left(\mathrm{R}^{2}=48.16 \%\right)$ did not show a significant influence of cultivar or year on observed variability in SRP quantity (Fig. 3). However, the sampling time ( $F=7.21)$ and interaction between sampling time and year $(\mathrm{F}=$ 109.4) significantly contributed to explaining variance with $\mathrm{p}<0.05$ (Supplementary Table 4).

SRP species present in the samples

Pectobacterium atrosepticum was the most abundant species in the examined seed lots and present in nearly 
all lots, except for the Asterix and Lady Claire P2 samples in 2016 (Table 2). Meanwhile, P. parmentieri was sporadically present in the seed lots examined in 2015 and 2016, and absent in the 2017 seed lots, except for one sample from the Lady Claire seed lot of unknown quality. A full overview of the number of subsamples that contained a certain amount of $P$. atrosepticum, P. parmentieri and D. solani can be found in Supplementary Table 2. No seed lot contained high amounts (Quantification cycle $[\mathrm{Cq}]<28$ ) of $P$. parmentieri in all tested subsamples, but high amounts were measured in approx. $3 \%$ of all subsamples (Supplementary Table 2). By comparison, approx. $73 \%$ of all subsamples contained high amounts of $P$. atrosepticum $(\mathrm{Cq}<28)$. D. solani was not detected in any of the seed lots at any sampling point (Table 2).

\section{Blackleg incidence}

In all years, blackleg symptomatic plants were observed towards the end of the growing season (Fig. 4). The total percentages of plants with clear blackleg symptoms were $0.6 \%$ in $2015,1.2 \%$ in 2016, and $0.5 \%$ in 2017 . Asterix consistently showed the largest overall proportion of symptomatic plants in all three years $(1.7 \%$ on average), and Innovator showed no symptoms in 2015 and 2017, and a very low percentage of plants that developed blackleg in $2016(0.1 \%)$. While plants grown from $\mathrm{P} 2$ seeds were generally free from symptoms or showed very low incidence of blackleg, the replanted tubers harvested from the 2016 Asterix P2 seed lot (Asterix, 2017, "P3") showed a 2\% incidence of blackleg symptoms. Otherwise, the seed classifications did not determine the blackleg incidence reliably. For plants from B1 seeds of Lady Claire, high incidence was observed in 2016, while the offspring tubers produced plants that were without blackleg symptoms in 2017 ("B2"). Overall, blackleg occurrence varied with the seed lot and potato cultivar, and to a lesser extent between years and seed quality, apart from P2.

\section{Soft rot incidence on tubers}

The number of samples that contained rotten tubers and the number of rotten tubers in those samples was assessed by visual inspection (Table 3 , Supplementary Fig. 1). Tubers with soft rot symptoms were observed for almost all tested seed lots in all years. However, there were only two cases where soft rot incidence was found in all samples (25 tubers per sample) of one seed lot (Supplementary Fig. 1). Before planting, only $1.6 \%$ of samples contained symptomatic tubers over all three years (Table 3 ). However, at harvest and after three months of storage, the percentage of samples with symptomatic tubers rose to 17.8 and $15.5 \%$ respectively. Over the three years, the total percentages of samples with symptomatic tubers increased from $9.2 \%$ in $2015,11.4 \%$ in 2016 , and to $16.2 \%$ in 2017. Except for 2016, Innovator tubers showed the lowest number of samples with symptomatic tubers. Planted P2 tubers and their harvested offspring, showed no samples with symptomatic tubers in 2016, except for one Innovator sample at harvest. In 2017, Asterix and Lady Claire P2 had one sample with soft rot symptoms at harvest and Asterix had two after storage, while the P2 seed lots of Innovator remained entirely free of disease incidence (Supplementary Fig. 1). The highest number of symptomatic tubers was found after storage in the Innovator B1 seed lot in 2016 and the Lady Claire seed lot of unknown quality in 2017.

Tuber infection of 15 potato cultivars at two different temperatures

To test different potato cultivars for tuber susceptibility to Pectobacterium, tubers were infected with two different strains of Pectobacterium and incubated in a controlled environment at two temperatures. Large overall differences in the amount of tissue rotten by $P$. atrosepticum and $P$. polaris were observed at 20 and $24{ }^{\circ} \mathrm{C}$ (Fig. 5). At $24{ }^{\circ} \mathrm{C}$, P. polaris macerated more tissue on average in 13 out of 15 cultivars, whereas $P$. atrosepticum macerated more tissue on average at $20{ }^{\circ} \mathrm{C}$ in 10 out of 15 cultivars, albeit with smaller margins. Table 4 shows the results of the ANOVA $\left(\mathrm{R}^{2}=73.8 \%\right)$ according to which all factors and factor interactions significantly contributed to the observed variability in tissue maceration. A visualization of the measured means and the estimated mean maceration values for the main factors cultivar, temperature, and strain, as well as interaction effects is provided in Supplementary Fig. 2. Grouping by pairwise comparisons indicated that Berber and Innovator each were statistically distinct from the other tested varieties (Table 5). Innovator was least susceptible to the tested strains, the cultivar Berber was macerated significantly more than any other cultivar. Other cultivars showed significant 

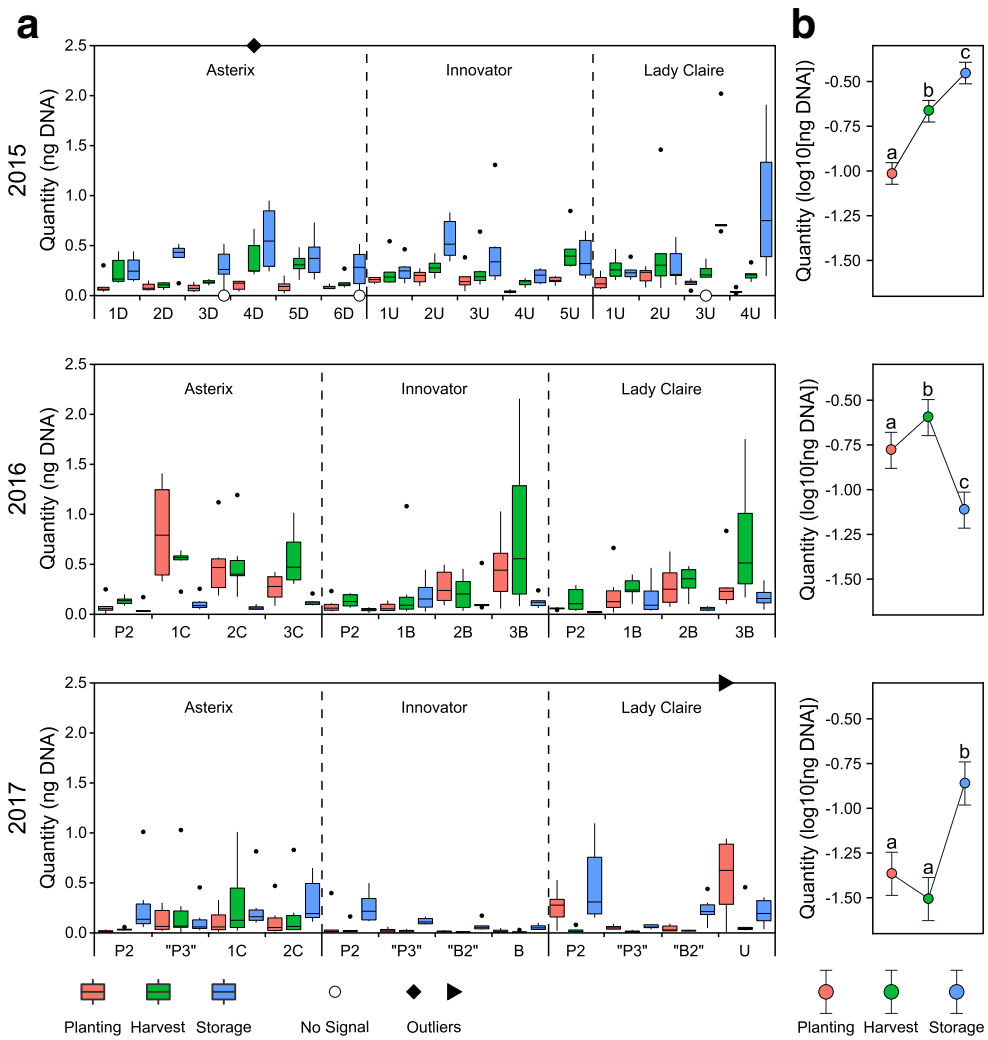

Fig. 1 SRP infection prevalence in the tested potato seed lots for each of the years 2015-2017. (a) SRP quantity in ng DNA for examined seed lots of the potato cultivars Asterix, Lady Claire and Innovator. Seed lot quality and identity (x-axes) is described in detail in Table 1. The quantity of SRP was calculated from qPCR results using the generic PEC assay after vacuum incubation enrichment. The colours of individual bars indicate the three sampling stages, planting (red boxes), harvest (green boxes), and after 3 months of storage (blue boxes). The boxes indicate the median (black line) and the first and third quartile, with the whiskers indicating the 1.5 inter-quartile range. Dots indicate

values outside this range (outliers). Two outliers outside the range of the diagram are indicated by a diamond in 2015 (12.9 ng) and an arrowhead in 2017 (5.6 ng). Replicates with no detectable signal (0 ng) are emphasized by white circles. (b) The average quantities of SRP for each year at the three sampling points: planting (red dots); harvest (green dots); after 3 months of storage (blue dots). Whiskers indicate the intervals calculated from the pooled standard deviations. Letters above the intervals indicate grouping according to Tukey pairwise comparisons with a $95 \%$ confidence interval

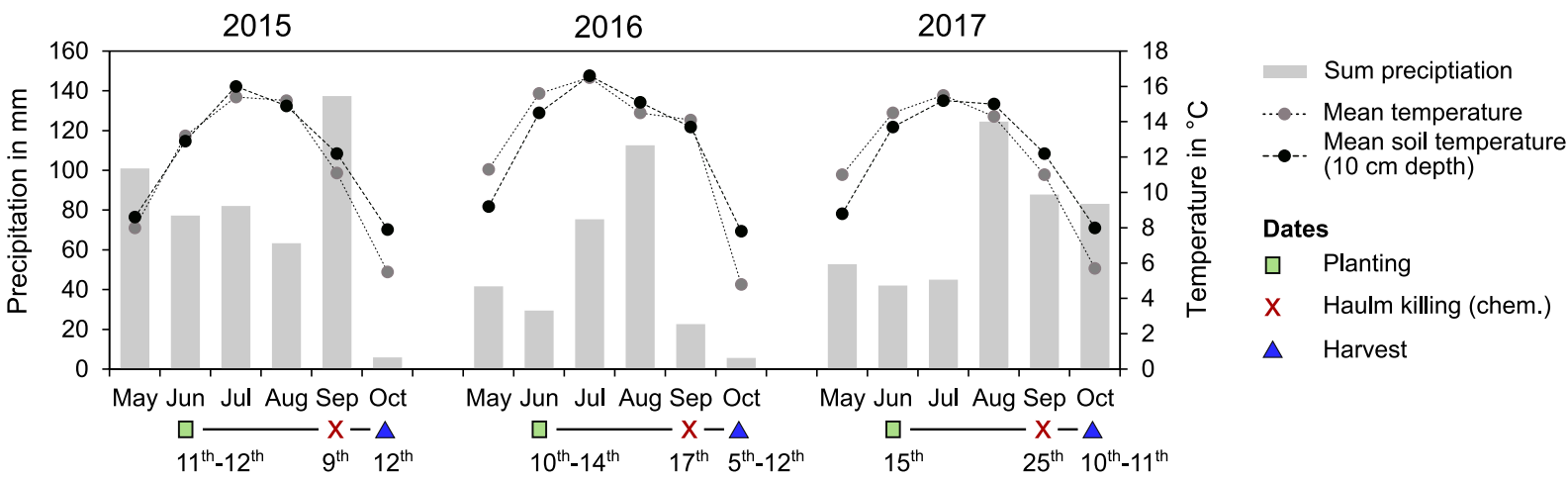

Fig. 2 Weather conditions at the field location during the growing seasons 2015-2017. Shown are the total precipitation in $\mathrm{mm}$ (light grey bars), mean air temperature in ${ }^{\circ} \mathrm{C}$ (grey dots), and mean soil

temperature at $10 \mathrm{~cm}$ depth in ${ }^{\circ} \mathrm{C}$ (black dots) for the months May - October (abbreviated). In addition, the dates (days) of planting, haulm killing and harvest are given for each year 


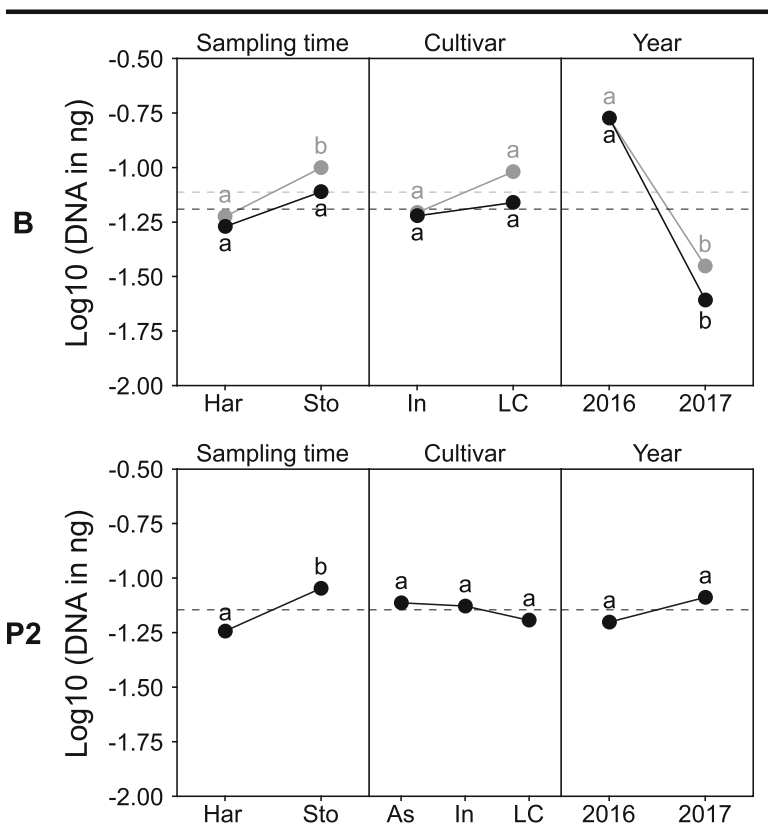

Fig. 3 Main effects in ANOVA models for factors in SRP infection prevalence of seed lots of qualities B and P2 in 2016 and 2017. Shown are the estimated means according to a mixed model based on the data shown in Fig. 1. The three examined main factors were the sampling times at harvest (Har) and after storage (Sto), the three investigated cultivars Asterix (As), Innovator (In) and Lady Claire (LC), and the year of sampling. Models were calculated separately for B-quality seed lots (top) without replanted seeds (black) and with replanted seed lots (grey) and for P2 quality seed lots (bottom). Overall estimated means are indicated by dotted lines. Model details are shown in Supplementary Table 4 . Letters indicate grouping according to Tukey pairwise comparisons with a $95 \%$ confidence interval

differences, but did not cluster into distinct groups like Innovator and Berber. When taking all factors into account in a pairwise comparison, all samples except those with the highest and lowest estimated means, belonged to multiple groups, and did not show a clear split of groups according to a single factor (Supplementary Table 5).

Temperature was the most impactful factor in the progression of soft rot in this experiment as indicated by the F-value of temperature compared to the other factors in the ANOVA model (Table 4). While the impact of the infecting strain was significant (Table 4), the difference between the two was much larger at $24{ }^{\circ} \mathrm{C}$ than at $20{ }^{\circ} \mathrm{C}$ (Fig. 5). On average, Lady Claire was significantly more susceptible than Asterix and Innovator (Table 5). However, for some conditions, e.g. $20^{\circ} \mathrm{C}$ and infection with P. polaris, Asterix, Lady Claire and Innovator were not significantly different (Supplementary Table 5).

\section{Discussion}

The presence of SRP in all seed lots demonstrated a widespread potential for disease development (Fig. 1A). Even the P2 lots that were included in 2016 and 2017 to offer a baseline, and contrast to the seed lots in 2015, contained some SRP, albeit in lower quantities compared to most other certified material.

In the identification of present SRP species by species-specific qPCR assays, $P$. atrosepticum was found in nearly all tested seed lots over the three years (Table 2). Notable exceptions were the Asterix P2 seed lot at planting and the Lady Claire P2 seed lots at planting and after storage in 2016, which did not contain any of the three SRP species that were tested for. There is currently no specific PCR test available for $P$. c. subsp. carotovorum, probably due to its high taxonomic variety. However, it must be assumed that this species was present with a similar distribution as $P$. atrosepticum based on previous sampling of infected Norwegian potato tubers and plants (Dees et al. 2017a). In contrast to P. atrosepticum, P. parmentieri was far less prevalent, suggesting a lesser impact of this species on disease incidence in this study. Furthermore, a DNA based assay to test for the presence of $P$. polaris was not available since the species was only recently described (Dees et al. 2017b). In a previous survey of Norwegian SRP strains, one out of 20 Norwegian P. c. subsp. carotovorum isolates was later identified as $P$. polaris (Dees et al. 2017a; Dees et al. 2017b). This allows the speculation that $P$. polaris had a low prevalence in the group of unidentified SRP species of the seed lots, if it was present at all. While D. solani was previously detected on two occasions, Dickeya species are generally not found in Norwegian potatoes (Dees et al. 2017a). The total absence of $D$. solani in all samples was therefore concurrent with expectations.

Overall trends of SRP infection prevalence in tubers before planting, at harvest, and after storage varied heavily between the years (Fig. 1B). In all years, haulm destruction and harvest were conducted mid-September and mid-October respectively, but the weather during the growing seasons varied over the three years (Fig. 2). This suggests substantial impact of the environmental conditions during the experiment. The most pronounced difference between the three years that are likely to impact SRP prevalence was the higher precipitation in 2015 and 2017, compared to 2016, particularly late in the growing season. In 2015, the overall and September 
Table 2 Presence of $P$. atrosepticum, P. parmentieri and D. solani at planting, harvest, and after storage in the examined potato seed lots after enrichment. Seed lots are organized by year and cultivar, and identified as detailed in Table 1. Quantities are indicated according to their quantification cycle $(\mathrm{Cq})$ values according to species-specific qPCR assays. This was distinguished as follows: all samples had a $\mathrm{Cq}<28(+++)$; at least one sample had a $\mathrm{Cq}<28$ $(++)$; at least one sample had a $\mathrm{Cq}<35(+)$; all samples had no signal or a $\mathrm{Cq}>35(0)$

\begin{tabular}{|c|c|c|c|c|c|c|c|c|c|}
\hline \multirow[b]{2}{*}{ Year } & \multirow[b]{2}{*}{ Cultivar } & \multirow[b]{2}{*}{$\begin{array}{l}\text { Seed lot } \\
\text { quality }\end{array}$} & \multicolumn{3}{|c|}{ P. atrosepticum } & \multicolumn{3}{|c|}{ P. parmentieri } & \multirow{2}{*}{$\frac{\text { D. solani }}{\text { All }}$} \\
\hline & & & Planting & Harvest & Storage & Planting & Harvest & Storage & \\
\hline \multirow[t]{15}{*}{2015} & \multirow[t]{6}{*}{ Asterix } & $1 \mathrm{D}$ & +++ & +++ & +++ & 0 & + & 0 & 0 \\
\hline & & $2 \mathrm{D}$ & +++ & +++ & +++ & ++ & 0 & 0 & 0 \\
\hline & & $3 \mathrm{D}$ & +++ & ++ & +++ & 0 & + & + & 0 \\
\hline & & $4 \mathrm{D}$ & ++ & +++ & +++ & 0 & 0 & 0 & 0 \\
\hline & & $5 \mathrm{D}$ & ++ & +++ & +++ & ++ & 0 & 0 & 0 \\
\hline & & $6 \mathrm{D}$ & +++ & +++ & +++ & ++ & ++ & 0 & 0 \\
\hline & \multirow[t]{5}{*}{ Innovator } & $1 \mathrm{U}$ & ++ & +++ & +++ & + & ++ & 0 & 0 \\
\hline & & $2 \mathrm{U}$ & ++ & ++ & ++ & ++ & 0 & 0 & 0 \\
\hline & & $3 \mathrm{U}$ & +++ & ++ & ++ & ++ & 0 & 0 & 0 \\
\hline & & $4 U$ & ++ & ++ & +++ & + & 0 & 0 & 0 \\
\hline & & $5 \mathrm{U}$ & ++ & +++ & ++ & 0 & ++ & 0 & 0 \\
\hline & \multirow[t]{4}{*}{ Lady Claire } & $1 \mathrm{U}$ & ++ & +++ & +++ & 0 & 0 & 0 & 0 \\
\hline & & $2 \mathrm{U}$ & +++ & ++ & +++ & + & ++ & ++ & 0 \\
\hline & & $3 \mathrm{U}$ & +++ & +++ & +++ & + & + & 0 & 0 \\
\hline & & $4 U$ & ++ & +++ & +++ & 0 & 0 & + & 0 \\
\hline \multirow[t]{12}{*}{2016} & \multirow[t]{4}{*}{ Asterix } & $\mathrm{P} 2$ & 0 & +++ & ++ & 0 & 0 & 0 & 0 \\
\hline & & $1 \mathrm{C}$ & +++ & +++ & +++ & + & 0 & + & 0 \\
\hline & & $2 \mathrm{C}$ & +++ & +++ & +++ & + & 0 & 0 & 0 \\
\hline & & $3 \mathrm{C}$ & +++ & +++ & +++ & ++ & + & 0 & 0 \\
\hline & \multirow[t]{4}{*}{ Innovator } & $\mathrm{P} 2$ & ++ & +++ & ++ & ++ & 0 & 0 & 0 \\
\hline & & $1 \mathrm{~B}$ & +++ & ++ & +++ & + & 0 & ++ & 0 \\
\hline & & $2 \mathrm{~B}$ & ++ & +++ & +++ & 0 & 0 & 0 & 0 \\
\hline & & $3 \mathrm{~B}$ & +++ & ++ & ++ & + & 0 & 0 & 0 \\
\hline & \multirow[t]{4}{*}{ Lady Claire } & $\mathrm{P} 2$ & 0 & ++ & 0 & 0 & 0 & 0 & 0 \\
\hline & & $1 \mathrm{~B}$ & +++ & ++ & + & 0 & 0 & 0 & 0 \\
\hline & & $2 \mathrm{~B}$ & +++ & +++ & + & + & 0 & 0 & 0 \\
\hline & & $3 \mathrm{~B}$ & ++ & +++ & ++ & 0 & 0 & 0 & 0 \\
\hline \multirow[t]{12}{*}{2017} & \multirow[t]{4}{*}{ Asterix } & $\mathrm{P} 2$ & ++ & ++ & +++ & 0 & 0 & 0 & 0 \\
\hline & & "P3" & ++ & ++ & ++ & 0 & 0 & 0 & 0 \\
\hline & & $1 \mathrm{C}$ & ++ & ++ & +++ & 0 & 0 & 0 & 0 \\
\hline & & $2 \mathrm{C}$ & ++ & ++ & +++ & 0 & 0 & 0 & 0 \\
\hline & \multirow[t]{4}{*}{ Innovator } & $\mathrm{P} 2$ & ++ & ++ & +++ & 0 & 0 & 0 & 0 \\
\hline & & "P3" & ++ & ++ & +++ & 0 & 0 & 0 & 0 \\
\hline & & "B2" & ++ & ++ & ++ & 0 & 0 & 0 & 0 \\
\hline & & B & + & + & ++ & 0 & 0 & 0 & 0 \\
\hline & \multirow[t]{4}{*}{ Lady Claire } & $\mathrm{P} 2$ & + & +++ & +++ & 0 & 0 & 0 & 0 \\
\hline & & "P3" & ++ & + & ++ & 0 & 0 & 0 & 0 \\
\hline & & "B2" & + & +++ & +++ & 0 & 0 & 0 & 0 \\
\hline & & $\mathrm{U}$ & ++ & ++ & +++ & ++ & 0 & 0 & 0 \\
\hline
\end{tabular}




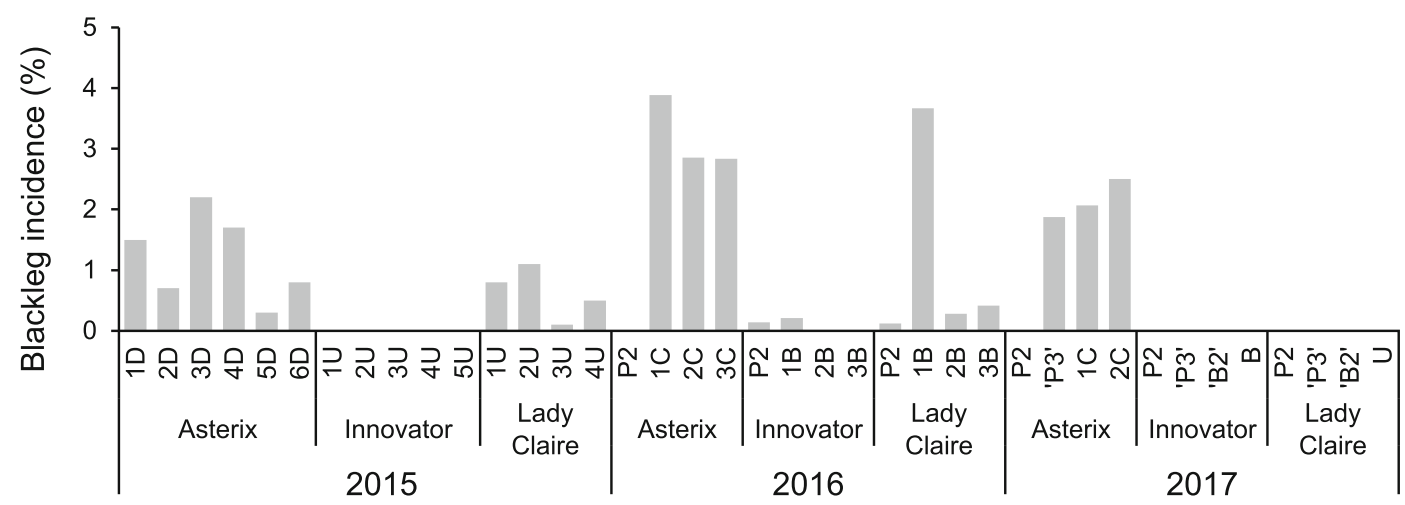

Fig. 4 Blackleg incidence in the field for three potato cultivars in late summer over three years. The incidence is shown as the percentage of symptomatic plants out of the total number of plants

precipitation was highest. High precipitation might weaken the tubers' defences by creating low oxygen conditions through waterlogging (Burton and Wigginton 1970; Pérombelon and Lowe 1975). This could be impactful late in the growing season, particularly after haulm destruction, when bacteria can multiply

Table 3 Soft rot incidence in the analysed samples at planting, harvest and after storage in 2015, 2016 and 2017 according to visual inspection. Given is the percentage of samples where one or more tubers showed soft rot symptoms, as well as the percentage of tubers with soft rot incidence. These percentages are given for each sampling time and year, each sampling time in total, and each year in total. The numerical amounts of soft rot symptomatic tubers per 25-tuber sample that these values are based on are shown in Supplementary fig. 1

\begin{tabular}{llll}
\hline \multirow{3}{*}{ Planting } & \multicolumn{3}{l}{ Soft rot incidence } \\
\hline \multirow{5}{*}{ Harvest } & 2015 & \% of samples & \% of tubers \\
& 2016 & 3 & 0.1 \\
& 2017 & 0 & 0.1 \\
& Total & $\mathbf{1 . 6}$ & 0 \\
& 2015 & 11.7 & $\mathbf{0 . 1}$ \\
Storage & 2016 & 19.4 & 1.1 \\
& 2017 & 26.4 & 0.9 \\
& Total & $\mathbf{1 7 . 8}$ & 2 \\
& 2015 & 14.2 & $\mathbf{1 . 3}$ \\
Total & 2016 & 11.1 & 1 \\
& 2017 & 22.2 & 2 \\
& Total & $\mathbf{1 5 . 5}$ & 2.4 \\
& 2015 & 9.2 & $\mathbf{1 . 7}$ \\
\hline
\end{tabular}

for a given seed lot. The seed lots are split by year and cultivar. For each seed lot, the seed quality according to the Norwegian seed certification scheme is given as indicated in Table 1

on the dying plant organs and may wash into the soil or form aerosols under heavy rainfall (Quinn et al. 1980; Burgess et al. 1994). In addition, wet soil may promote the spread of SRP through active motility of the bacteria or washing of the bacteria from diseased to healthy material. At harvest, moisture may promote contamination of healthy tubers by increasing smearing of bacteria via machines, tools and direct contact.

Normally, it is expected that under good storage conditions, SRP infection in tubers decreases over time (van Vuurde and de Vries 1994), as was observed in 2016 (Fig. 1B). The synopsis of weather and SRP infection prevalence overall suggests that high precipitation during the growing season, particularly close to harvest, compromises the ability of the tubers to fend off SRP and/or may increase the risk of transmission between tubers. Conversely, a dryer growing season and harvest window might promote tuber defence throughout storage and provide seed with relatively lower SRP quantity in the next season.

In the ANOVA of prevalence data, the factor 'year' was used as a proxy for environmental conditions (Fig. 3 ). While the used model cannot differentiate e.g. precipitation and temperature, the effect of the year is synonymous with all environmental differences between 2016 and 2017. As discussed above, the large differences in late season precipitation are likely the most impactful for SRP prevalence and disease incidence. The strong impact of the year on the observed SRP prevalence and insignificant contribution of cultivar in B-quality seed in 2016 and 2017 therefore further supports a major role of the environment, particularly late season precipitation, on SRP prevalence (Fig. 3). The ANOVA of prevalence data for those seed lots 


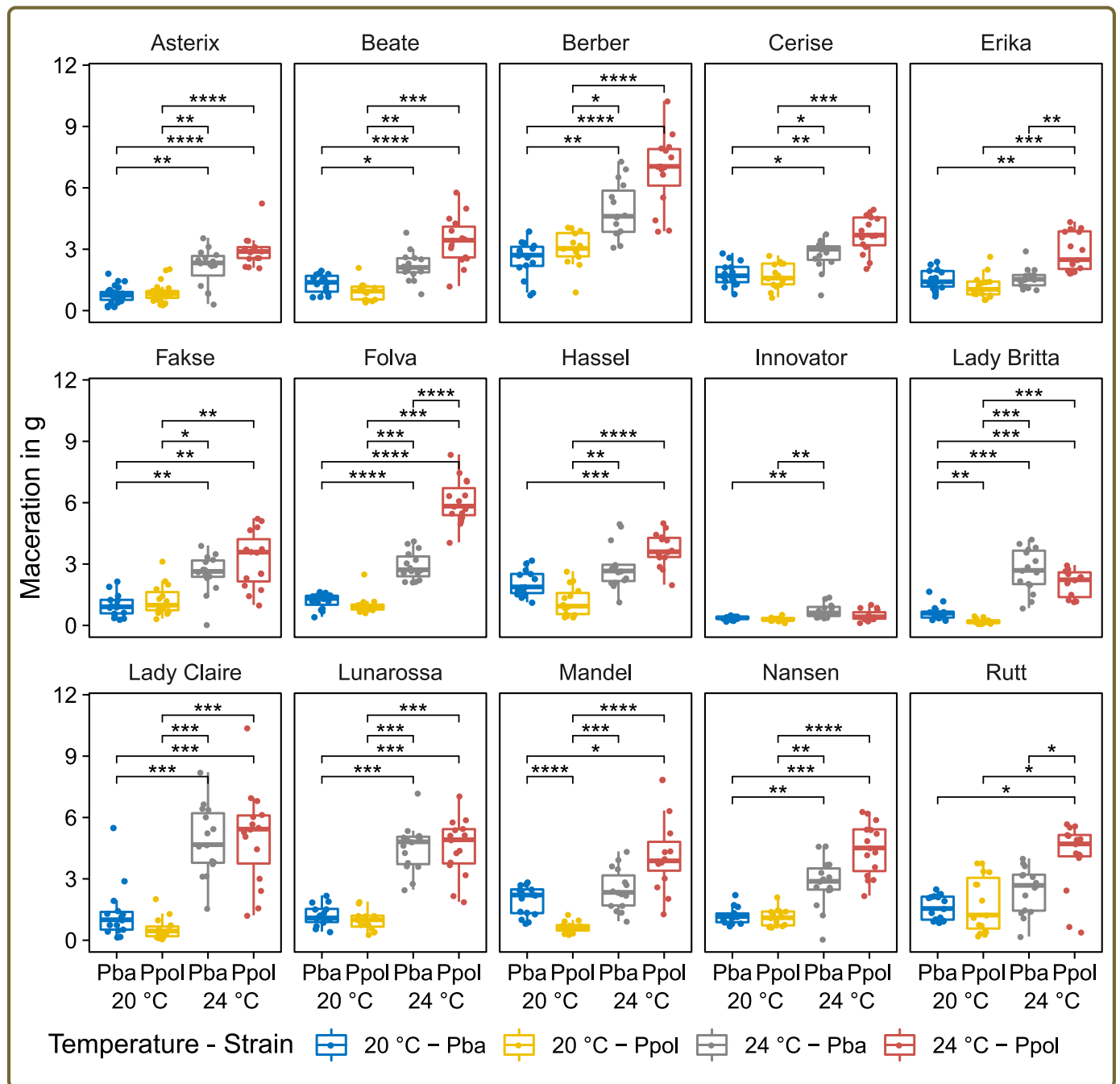

Fig. 5 Amount of macerated tuber tissue from 15 potato cultivars at two different temperatures three days after inoculation with two different Pectobacterium strains. Shown is the macerated tissue in $\mathrm{g}$ of 15 tubers per sample. $\mathrm{Pba}$ and Ppol refer to the two strains P. atrosepticum strain PK-782-1-2-13 and P. polaris NIBIO1006, infections with both strains are shown for incubation at $20^{\circ} \mathrm{C}$ and $24^{\circ} \mathrm{C}$. The boxes indicate the median (line within box) and the first and third quartile with the whiskers indicating 1.5 upper and lower

shows a bigger difference between years than between harvest and storage, although the two sampling points were significantly different when replanted seed lots were included in the analysis. The replanted seed lots did not count as certified B-quality seeds since they were grown and stored in the context of this experiment and not by a certified seed grower. However, they may still be considered of comparable health according to their age, and lower or comparable SRP prevalence, blackleg incidence and soft rot incidence in both inter-quartile range. Dots indicate individual values for one tested tuber per dot. Significant differences in pairwise comparisons using the Wilcoxon test and adjustment of the $p$ value for the familywise error rate using the Holm-Bonferroni method are shown above the bars in each panel $(*$ for adjusted $p$ value $<0.05, * *$ for adj. $p<0.01, * * *$ for $\operatorname{adj} . p<0.001$, **** for adj. $p<0.0001)$

Innovator and Lady Claire (Figs. 1 and 4, Supplementary Fig. 1). While late season precipitation seems to have increased SRP prevalence in storage, previous studies from Poland and Finland report that warm, dry summers increase the prevalence of $D$. solani (Degefu et al. 2013; Potrykus et al. 2016). ANOVA of P2-quality seed lots did not suggest a significant contribution of cultivar or year on the observed variability in SRP prevalence (Fig. 3). This was attributed to the reliably low SRP prevalence in the P2 seed lots. 
Table 4 Results from fitting the ANOVA model to the tuber infection test data using cultivar, temperature, strain, and all their interactions as independent factors. Given are the degrees of freedom (DF), adjusted sum of squares (Adj. SS), adjusted mean squares (Adj. MS), F-value, and $p$ value associated with each factor

\begin{tabular}{|c|c|c|c|c|c|}
\hline Source & DF & Adj. SS & Adj. MS & F-value & $P$ value \\
\hline Cultivar & 14 & 606.5 & 43.3 & 49.6 & 0.000 \\
\hline Temperature & 1 & 1011.6 & 1011.6 & 1158.4 & 0.000 \\
\hline Strain & 1 & 34.7 & 34.7 & 39.8 & 0.000 \\
\hline Cultivar*Temperature & 14 & 215.7 & 15.4 & 17.6 & 0.000 \\
\hline Cultivar*Strain & 14 & 64.7 & 4.6 & 5.3 & 0.000 \\
\hline Temperature*Strain & 1 & 92.4 & 92.4 & 105.9 & 0.000 \\
\hline Cultivar*Temperature*Strain & 14 & 56.1 & 4.0 & 4.6 & 0.000 \\
\hline Error & 867 & 757.1 & 0.9 & & \\
\hline Total & 926 & 2888.8 & & & \\
\hline
\end{tabular}

However, P2 seed lots varied significantly between sampling times (Fig. 3). Changes between harvest and storage largely followed the average trends for 2016 and 2017 , leading to a significant impact and high F-value of the factor interaction between year and sampling time in the model for B and P2 quality seed lots (Supplementary Table 4). Based on the overall SRP prevalence shown in Fig. 1A, the cultivar may contribute to the prevalence in spite of the results of the ANOVA; for instance, prevalence was often lowest in Innovator. However, since the

Table 5 Grouping results from Tukey's pairwise comparisons, using 5\% significance level, of the main effects of the cultivars based on the ANOVA model fitted to the tuber infection test data. Given are the number of observations $(\mathrm{N})$ and the estimated mean seed lot qualities were too uneven between cultivars and often unknown, the overall effect of the cultivar on prevalence could not be reliably tested here.

The influence of the weather conditions during the growing season on long-term seed tuber health may explain some of the observations made in the assessment of blackleg incidence (Fig. 4). The high overall blackleg incidence in 2016 may reflect the compromised seed tuber health of the mother tubers grown in 2015. Similarly, the total absence of blackleg incidence

macerated tissue in $\mathrm{g}$ (Mean in g). Cultivars that do not share a letter indicate that they are significant different, based on the estimated means

\begin{tabular}{|c|c|c|c|c|c|c|c|c|c|c|}
\hline Cultivar & $\mathbf{N}$ & Mean in $g$ & Grouping & & & & & & & \\
\hline Berber & 58 & 4.3 & A & & & & & & & \\
\hline Lady Claire & 60 & 3.0 & & B & & & & & & \\
\hline Lunarossa & 60 & 2.8 & & B & $\mathrm{C}$ & & & & & \\
\hline Folva & 60 & 2.8 & & B & $\mathrm{C}$ & & & & & \\
\hline Cerisa & 60 & 2.5 & & B & $\mathrm{C}$ & $\mathrm{D}$ & & & & \\
\hline Rutt & 60 & 2.5 & & B & $\mathrm{C}$ & $\mathrm{D}$ & & & & \\
\hline Hassel & 60 & 2.4 & & B & $\mathrm{C}$ & $\mathrm{D}$ & & & & \\
\hline Nansen & 60 & 2.4 & & B & $\mathrm{C}$ & $\mathrm{D}$ & & & & \\
\hline Mandel & 60 & 2.3 & & & $\mathrm{C}$ & $\mathrm{D}$ & $\mathrm{E}$ & & & \\
\hline Fakse & 60 & 2.0 & & & & $\mathrm{D}$ & $\mathrm{E}$ & $\mathrm{F}$ & & \\
\hline Beate & 60 & 2.0 & & & & $\mathrm{D}$ & E & $\mathrm{F}$ & G & \\
\hline Erika & 60 & 1.8 & & & & & E & $\mathrm{F}$ & G & \\
\hline Asterix & 89 & 1.7 & & & & & & $\mathrm{~F}$ & $\mathrm{G}$ & \\
\hline Lady Britta & 60 & 1.4 & & & & & & & G & \\
\hline Innovator & 60 & 0.5 & & & & & & & & $\mathrm{H}$ \\
\hline
\end{tabular}


in Lady Claire plants in 2017 may be explained by the lower SRP prevalence in mother tubers grown in a drier weather during the growing season 2016. Blackleg incidence in 2015 may also have been driven by the high consistent precipitation early on in the growing period. Moreover, the blackleg incidence seems to have been influenced by potato cultivar. Plants from all Asterix seed lots, except for P2 quality seeds, developed blackleg in all years, while Innovator rarely developed any, despite the presence of SRP in the tubers. Lady Claire plants performed overall worse than Innovator but better than Asterix in blackleg incidence, and had no symptomatic plants in 2017. Innovator and Lady Claire might have a lower susceptibility to blackleg, than Asterix. However, the seed grade of Asterix tubers was generally worse than for the other two cultivars, making such conclusions difficult. Although the average blackleg incidence was not dramatically high in any of the years, it is important to note, that an incidence of more than $1 \%$ disqualifies seed lots from certification under the Norwegian certification scheme, which leads to substantial financial losses for seed growers.

Tubers with soft rot symptoms were counted in the samples used for the SRP quantification (Supplementary Fig. 1). The seed lots with a high number of samples containing symptomatic tubers did not correspond to the seed lots with high blackleg incidence (Fig. 4, Supplementary Fig. 1). Since the bacteria can rapidly spread and elicit symptoms in previously healthy tubers, the number of rotten tubers in one sample is less informative than the number of samples with any rotten tubers. The trends from the SRP quantification (Fig. 1) are somewhat reflected in the soft rot occurrence (Table 3). In 2015 and 2017, the percentage of samples with soft rot incidence increased from harvest to storage, while it decreased overall in 2016. This further supports the notion that the precipitation late in the growing season has an overall influence on the resilience of tubers in storage. Innovator seems to be least susceptible among the three cultivars tested in the field, based on the low blackleg incidence and mostly low amount of soft rot incidence. Earlier work in Switzerland showed Innovator to be susceptible to blackleg in the field after inoculation with Dickeya spp., with large variations between years that were similar to other cultivars (Rouffiange et al. 2014; Gill et al. 2014). The low susceptibility of Innovator to blackleg observed here may be specific to Norwegian conditions, where the growing season is comparatively short with cool weather conditions, and
Pectobacterium species, particularly P. atrosepticum are predominant (Table 2) (Dees et al. 2017a).

P2 seed lots displayed reliably low blackleg and soft rot incidence (Fig. 4 and Supplementary Fig. 1), and largely low SRP prevalence (Fig. 1). With the exception of P2 seeds, the certification grades displayed inconsistent behaviour between the years and tested cultivars regarding disease incidence and SRP prevalence. The observations in the replanted seed lots in 2016 and 2017 suggest that disease incidence and SRP prevalence are unreliable indicators of a seed lots performance in future growing seasons. Most replanted seed lots performed comparable or better in 2017 for SRP prevalence and disease incidence.

The attempt to fit regression models to the data for disease incidence with infection prevalence as a regressor were unsuccessful (not shown). As a result, the measured prevalence in the presented form could not be used to predict disease outcomes. The use of halved tubers and enrichment using inexpensive instruments (vacuum sealer, suitable plastic bags) is cost-efficient, quick, and yields samples that are easier to quantify, compared to industrial scale skin peeling and SRP extraction, which was previously suggested (Pérombelon 2000). Furthermore, testing just the skin and stolon heel was shown to miss a significant part of the tuber-associated inoculum (Boomsma et al. 2013). With the method chosen in this work, SRP could be detected, regardless of their localisation in or on the tubers. The incubation employed here may have favoured the multiplication of other pathogens which may be in competition with SRP, or certain SRP species over others (Kõiv et al. 2015). The multiplication rate of SRP in the used vacuum enrichment method, and how it is influenced by other present microbes, is not known. Therefore, the qPCR assay after enrichment in the presented form is not necessarily suited to quantify the initial amount of SRP. However, the chosen method quantified the prevalence of latent SRP with the potential to cause disease on a large scale. An improved workflow for prevalence measurement with direct enrichment, omitting the two-week incubation at $16{ }^{\circ} \mathrm{C}$ before analysis, could yield results, which can better predict field outcomes and disease incidence. Assessing the SRP prevalence by qPCR enabled large-scale analysis over various time points in the seed cycle, and facilitated the comparison between different seed lots. However, the prevalence data presented in Fig. 1 did not relate to the observed disease incidence. Diversified data, more sophisticated modelling approaches, e.g. incorporating machine learning, and improved standardized molecular testing of SRP infection prevalence may 
eventually yield reliable prediction tools for field outcomes and prevention strategies.

Tuber infection of 15 typical Norwegian cultivars with $P$. atrosepticum and $P$. polaris under controlled conditions contextualized the susceptibility of the three cultivars used in the field trial (Fig. 5). In the field, Innovator had less overall SRP prevalence, blackleg incidence and rotten samples than Asterix and Lady Claire. This was supported by a significantly lower susceptibility towards the tested Pectobacterium species in the infection assay. However, the tuber infection conducted here is not a sufficient indicator of the tested cultivars' abilities to withstand systemic infection and blackleg occurrence under field conditions, as shown previously for other cultivars (Lebecka et al. 2018; Wastie et al. 1988). It nevertheless offers insight into the hierarchy of factors in tuber soft rot and shows temperature to be the most important factor under controlled conditions, followed by potato cultivar and infecting strain, supporting similar findings of Lebecka et al. (2018). The importance of temperature in this experiment was demonstrated by the high F-value of temperature as a factor compared to the other factors in the three-way ANOVA (Table 4). It was further shown by the frequency of significant differences in tissue maceration between temperatures within a cultivar compared to infecting strain (Fig. 5). Notably, for blackleg caused by Dickeya spp. in various cultivars, field experiments showed environmental factors to have the biggest influence on days before disease occurrence, while host susceptibility and SRP aggressiveness played the biggest role in disease incidence (Gill et al. 2014). Norway has so far not experienced outbreaks of species like D. solani or P. c. subsp. brasiliense, which thrive at warmer temperatures (du Raan et al. 2016). The data presented here suggests that the tested $P$. polaris strain, an aggressive Norwegian isolate, has a higher optimal temperature range compared to the currently far more prevalent $P$. atrosepticum, which generally has a lower temperature range (Fig. 5) (du Raan et al. 2016). The temperature range of $P$. polaris seems to be more similar to what du Raan et al. (2016) found for P. parmentieri (then P. wasabiae). Zoledowska et al. (2018) also showed that $P$. parmentieri macerated potatoes (cv. 'Lord') more efficiently than P. atrosepticum in a slice assay at $28{ }^{\circ} \mathrm{C}$. While neither $P$. parmentieri nor $P$. polaris are currently as prevalent as $P$. atrosepticum in Norway, they are present in diseased potato plants and tubers (Table 2) (Dees et al. 2017a; Dees et al. 2017b).
Therefore, outbreaks of already present aggressive SRP variants may be expected in spite of strict seed import regulations and controls, as warmer growing seasons with heavy rainfalls and humid weather are predicted to occur more frequently (Hanssen-Bauer et al. 2009).

In conclusion, enrichment of SRP from halved tubers in vacuum and subsequent quantification by $\mathrm{qPCR}$ were implemented as a cost-efficient option for large-scale tuber testing and assessment of seed tuber health. Although, the obtained results did not reliably correlate with disease incidence, improvements in the workflow may yield data, which can be used in better diagnostic and predictive tools. The data presented here suggests that the weather during the growing season has the greatest impact on SRP quantity in the tubers under Norwegian conditions. Consequently, the presented data supports the two stated hypotheses. The ubiquity of SRP and seemingly inevitable acquisition in the field need to be addressed through higher volumes of clean early generation seed, stricter hygiene regimes and certification methods with better predictive value.

Acknowledgments This study was funded by a grant from Research Funding for Agriculture and the Food Industry Matfondavtale (244207), including support from the following industry partners: Bama Gruppen AS, Gartnerhallen SA, Norgro AS, 7 sense, Findus Norge AS, Totenpoteter AS, Orkla Confectionery \& Snacks Norge, Strand Unikorn AS, Tromspotet AS, Lærdal Grønt AS, Bayer As, Overhalla Klonavlssenter. We thank the reviewers for their vital contributions to the improvement of this work.

Compliance with ethical standards All authors have participated in the research and manuscript preparation, and all have reviewed and approved the manuscript. The manuscript has not been published before and has only been submitted to EJPP for evaluation.

Conflict of interest The authors declare that they have no conflict of interest.

Human and Animal Sudies This research did not involve human participants or animals.

\section{References}

Boomsma, D., Velvis, H., Kristelijn, K., van Tent Becking, T., Kastelein, P., van der Zouwen, P. S., et al. (2013). Deltaplan Erwinia. Deel C-pootaardappelen. Eindrapport van het 
onderzoek 2009-2012. Nederlands Aardappel Organisatie (NAO), Productschap Akkerbouw (PA).

Burgess, P., Blakeman, J., \& Perombelon, M. C. M. (1994). Contamination and subsequent multiplication of soft rot Erwinias on healthy potato leaves and debris after haulm destruction. Plant Pathology, 43(2), 286-299.

Burton, W. G., \& Wigginton, M. J. (1970). The effect of a film of water upon the oxygen status of a potato tuber. Potato Research, 13(3), 180-186.

Chung, Y. S., Goeser, N. J., Cai, X., \& Jansky, S. (2013). The effect of long term storage on bacterial soft rot resistance in potato. American Journal of Potato Research, 90(4), 351356.

Czajkowski, R., de Boer, W. J., van Veen, J. A., \& van der Wolf, J. M. (2010a). Downward vascular translocation of a green fluorescent protein-tagged strain of Dickeya sp. (biovar 3) from stem and leaf inoculation sites on potato. Phytopathology, 100(11), 1128-1137.

Czajkowski, R., de Boer, W. J., Velvis, H., \& van der Wolf, J. M. (2010b). Systemic colonization of potato plants by a soilborne, green fluorescent protein-tagged strain of Dickeya sp. biovar 3. Phytopathology, 100(2), 134-142.

Czajkowski, R., Pérombelon, M. C. M., Jafra, S., Lojkowska, E., Potrykus, M., van der Wolf, J. M., et al. (2015). Detection, identification and differentiation of Pectobacterium and Dickeya species causing potato blackleg and tuber soft rot: A review. The Annals of Applied Biology, 166(1), 18-38.

Czajkowski, R., Perombelon, M. C. M., van Veen, J. A., \& van der Wolf, J. M. (2011). Control of blackleg and tuber soft rot of potato caused by Pectobacterium and Dickeya species: A review. Plant Pathology, 60(6), 999-1013.

Dees, M. W., Lebecka, R., Perminow, J. I. S., Czajkowski, R., Grupa, A., Motyka, A., et al. (2017a). Characterization of Dickeya and Pectobacterium strains obtained from diseased potato plants in different climatic conditions of Norway and Poland. European Journal of Plant Pathology, 148(4), 839851.

Dees, M. W., Lysøe, E., Rossmann, S., Perminow, J., \& Brurberg, M. B. (2017b). Pectobacterium polaris sp. nov., isolated from potato (Solanum tuberosum). Int. J. Syst. Evol. Microbiol., 67(12), 5222-5229.

Degefu, Y., Potrykus, M., Golanowska, M., Virtanen, E., \& Lojkowska, E. (2013). A new clade of Dickeya spp. plays a major role in potato blackleg outbreaks in North Finland. Ann. Appl. Biol., 162(2), 231-241.

du Raan, S., Coutinho, T. A., \& van der Waals, J. E. (2016). Cardinal temperature differences, determined in vitro, between closely related species and subspecies of pectinolytic bacteria responsible for blackleg and soft rot on potatoes. European Journal of Plant Pathology, 144(2), 361-369.

Gill, E. D., Schaerer, S., \& Dupuis, B. (2014). Factors impacting blackleg development caused by Dickeya spp. in the field. Eur. J. Plant Pathol., 140(2), 317-327.

Glasner, J. D., Marquez-Villavicencio, M., Kim, H. S., Jahn, C. E., Ma, B., Biehl, B. S., Rissman, A. I., Mole, B., Yi, X., Yang, C. H., Dangl, J. L., Grant, S. R., Perna, N. T., \& Charkowski, A. O. (2008). Niche-specificity and the variable fraction of the Pectobacterium pan-genome. Molecular Plant-Microbe Interactions, 21(12), 1549-1560.

Hanssen-Bauer, I., Drange, H., Førland, E., Roald, L., Børsheim, K., Hisdal, H., et al. (2009). Climate in Norway 2100.
Background information to NOU climate adaptation (in Norwegian: Klima i Norge 2100. Bakgrunnsmateriale til NOU Klimatilplassing). Oslo: Norsk klimasenter.

Kassambara, A. (2019a). Ggpubr: 'ggplot2' based publication ready plots. https:/github.com/kassambara/ggpubr.

Kassambara, A. (2019b). Rstatix: Pipe-friendly framework for basic statistical tests in R. https://github. com/kassambara/rstatix.

Kõiv, V., Roosaare, M., Vedler, E., Ann Kivistik, P., Toppi, K., Schryer, D. W., et al. (2015). Microbial population dynamics in response to Pectobacterium atrosepticum infection in potato tubers. Scientific Reports, 5, 11606.

Laurila, J., Ahola, V., Lehtinen, A., Joutsjoki, T., Hannukkala, A., Rahkonen, A., et al. (2008). Characterization of Dickeya strains isolated from potato and river water samples in Finland. European Journal of Plant Pathology, 122(2), 213-225.

Lebecka, R., Flis, B., \& Murawska, Z. (2018). Comparison of temperature effects on the in vitro growth and disease development in potato tubers inoculated with bacteria Pectobacterium atrosepticum, P. carotovorum subsp. carotovorum and Dickeya solani. J. Phytopathol., 654-662.

Lyon, G. (1989). The biochemical basis of resistance of potatoes to soft rot Erwinia spp.-A review. Plant Pathol., 38(3), 313339.

Ma, B., Hibbing, M. E., Kim, H.-S., Reedy, R. M., Yedidia, I., Breuer, J., Breuer, J., Glasner, J. D., Perna, N. T., Kelman, A., \& Charkowski, A. O. (2007). Host range and molecular phylogenies of the soft rot enterobacterial genera Pectobacterium and Dickeya. Phytopathology, 97(9), 11501163.

Ma, X., Schloop, A., Swingle, B., \& Perry, K. L. (2018). Pectobacterium and Dickeya responsible for potato blackleg disease in New York state in 2016. Plant Disease, 1834 1840.

Ngadze, E., Coutinho, T. A., Icishahayo, D., \& van der Waals, J. E. (2014). Effect of calcium soil amendments on phenolic compounds and soft rot resistance in potato tubers. Crop Protect., $62,40-45$.

Pérombelon, M. C. M. (2000). Blackleg risk potential of seed potatoes determined by quantification of tuber contamination by the causal agent and Erwinia carotovora subsp. atroseptica: A critical review. EPPO Bulletin, 30(3-4), 413-420.

Pérombelon, M. C. M. (2002). Potato diseases caused by soft rot erwinias: An overview of pathogenesis. Plant Pathology, 51(1), 1-12.

Pérombelon, M. C. M., \& Kelman, A. (1987). Blackleg and other potato diseases caused by soft rot erwinias: Proposal for revision of terminology. Plant Disease, 71(3), 283-285.

Pérombelon, M. C. M., Lopez, M. M., Carbonell, J., \& Hyman, L. J. (1988). Effects of contamination by Erwinia carotovora subsp. carotovora and E. carotovora subsp. atroseptica of potato seed tubers and of cultivar resistance on blanking or nonemergence and blackleg development in Valencia, Spain. Potato Res., 31(4), 591-599.

Pérombelon, M. C. M., \& Lowe, R. (1975). Studies on the initiation of bacterial soft rot in potato tubers. Potato Research, 18(1), 64-82.

Pérombelon, M. C. M., Lumb, V. M., Zutra, D., Hyman, L. J., \& Burnett, E. M. (1989). Factors affecting potato blackleg 
development. In E. C. Tjamos \& C. H. Beckman (Eds.), Vascular wilt diseases of plants (pp. 421-431). Berlin, Heidelberg: Springer.

Potrykus, M., Golanowska, M., Sledz, W., Zoledowska, S., Motyka, A., Kolodziejska, A., et al. (2016). Biodiversity of Dickeya spp. isolated from potato plants and water sources in temperate climate. Plant Disease, 100(2), 408-417.

Pritchard, L., Humphris, S., Saddler, G. S., Parkinson, N. M., Bertrand, V., Elphinstone, J. G., et al. (2013). Detection of phytopathogens of the genus Dickeya using a PCR primer prediction pipeline for draft bacterial genome sequences. Plant Pathology, 62(3), 587-596.

Quinn, C. E., Sells, I. A., \& Graham, D. C. (1980). Soft rot Erwinia bacteria in the atmospheric bacterial aerosol. The Journal of Applied Bacteriology, 49(1), 175-181.

Rossmann, S., Dees, M. W., Perminow, J., Meadow, R., \& Brurberg, M. B. (2018). Soft rot Enterobacteriaceae are carried by a large range of insect species in potato fields. Appl Environ Microbiol (2018/04/08 ed., Vol. 84, pp. e00281-00218).

Rouffiange, J., Gerardin, D., Kellenberger, I., Schaerer, S., \& Dupuis, B. (2014). Potato susceptibility to blackleg disease caused by Dickeya spp. Agrarforschung Schweiz, 5(3), 96103.

Smadja, B., Latour, X., Trigui, S., Burini, J. F., Chevalier, S., \& Orange, N. (2004). Thermodependence of growth and enzymatic activities implicated in pathogenicity of two Erwinia carotovora subspecies (Pectobacterium spp.). Can. J. Microbiol., 50(1), 19-27.

van der Wolf, J. M., de Haan, E. G., Kastelein, P., Krijger, M., Haas, B. H., Velvis, H., et al. (2017). Virulence of Pectobacterium carotovorum subsp. brasiliense on potato compared with that of other Pectobacterium and Dickeya species under climatic conditions prevailing in the Netherlands. Plant Pathol., 66, 571-583.

van der Wolf, J. M., Nijhuis, E. H., Kowalewska, M. J., Saddler, G. S., Parkinson, N., Elphinstone, J. G., et al. (2014). Dickeya solani sp. nov., a pectinolytic plant pathogenic bacterium isolated from potato (Solanum tuberosum). Int. J. Syst. Evol. Microbiol, 64(3), 768-774.

van Vuurde, J. W. L., \& de Vries, P. M. (1994). Population dynamics of Erwinia carotovora subsp. atroseptica on the surface of intact and wounded seed potatoes during storage. J. Appl. Bacteriol., 76(6), 568-575.

Wastie, R. L., Jellis, G. J., Lapwood, D. H., Logan, C., Little, G., \& Phillips, M. S. (1988). Assessing potato cultivars for resistance to tuber soft rot (Erwinia carotovora subsp. atroseptica) at four test centres in the UK. Potato Res., 31(1), 67-72.

Wickham, H. (2016). ggplot2: Elegant Graphics for Data Analysis: Springer-Verlag New York.

Zoledowska, S., Motyka, A., Zukowska, D., Sledz, W., \& Lojkowska, E. (2018). Population structure and biodiversity of Pectobacterium parmentieri isolated from potato fields in temperate climate. Plant Disease, 102(1), 154-164. 